\title{
The Dual-Media Concept
}

\section{... saves money and space without sacrificing research effectiveness}

As viewed by Evan Farber, author of Classified List of Periodicals for the College Library (Faxon, $1957 \& 1970$ ) and a member of the Institute's Editorial Advisory Board,

"Because The Congressional Record and its predecessors contain so much information about the activities of Congress, including the votes and near-verbatim reporting of debates, it is an essential resource for all courses relating to American government and should, therefore, be available in every academic library. On the other hand, its very comprehensiveness not only creates a space problem for most libraries, but also results in disproportionately high acquisitions costs for new libraries attempting to acquire complete backfile runs.

Microfilm offers a partial solution in that it is less expensive initially and saves valuable shelf space. One of the major obstacles to its acceptance however, has been the fact that students and other researchers find that searching for references in microform indexes is inconvenient, time consuming, and ultimately discouraging to effective research.

"Having the Proceedings of Congress available then, in the Dual-Media Edition, with the proceedings and appendices on microfilm and the Sessional Indexes and Histories of Bills and Resolutions in printed form (the Record is almost useless without its Indexes), means that libraries can now offer the wealth of this resource plus the convenience of the Indexes in book format, yet use a minimum of space and money."

\section{THE UNITED STATES HISTORICAL DOCUMENTS INSTITUTE}

...has been founded in Washington, D.C. to republish complete collections of basic out-of-print historical reference materials in "Dual-Media Editions." Initially, special emphasis will be placed on those basic serials which have been recommended for new or expanding academic libraries which are building collections in the fields of U.S. History and Government. These "Dual-Media Editions" will be reproduced in optimum combinations of microfilm and baok formats to provide maximum gains in serials reference capacity at minimum cost.

\section{EDITORIAL ADVISORY BOARD}

This distinguished and representative Editorial Advisory Board has been organized to assist the Institute in its planning and program evaluation activities.
Sert. Warren Magnuson
(D-Wash.): Chmn., Sen. Commerce Comm.; Chmn., Subcomm. LaboruHEW Appropriations
Sen. Mark Hattiøld
(R.Ore.); Sen. Comm. on Inferior \& Insular Alfaies: Sen. Comm. on Aeronautical \& Space Sciences
Rep. John Brademas
(D-Ind.): House Education 8 Labor Comm.; Jt. Comm. on the Libr, of Cong.
Rep. Fred Schwengel
(R-lowa); Member, Jt. Comm. on the Libr. of Cong.; Comm. on House Administration
Evan Ira Farbar
Libn., Earlham Col.: 1968- 69 Dir., Col. Libr. Sec. ACRL
Dr. E. M. Kirkpatrick
Dr. Wm. Gostzmann
Exec. Dir., American Political Science Assn., Washington, D.C.
Dir. Depl. of Amer.
Studies, Univ. ol Texas:
Pulitzer Prize, History (1967)
Roger 5 mith Weekly, New York, N.Y.

Dual-media sets for each Congress and Session are also available, as are single microfilm reels and index volumes. Send for our detailed catalog listing individual units. All items are sold "on approval" and may be returned for credit within sixty days after delivery.

\section{USE THIS CONVENIENT PRICE SCHEDULE AS YOUR ORDER FORM FOR DUAL-MEDIA SETS.}

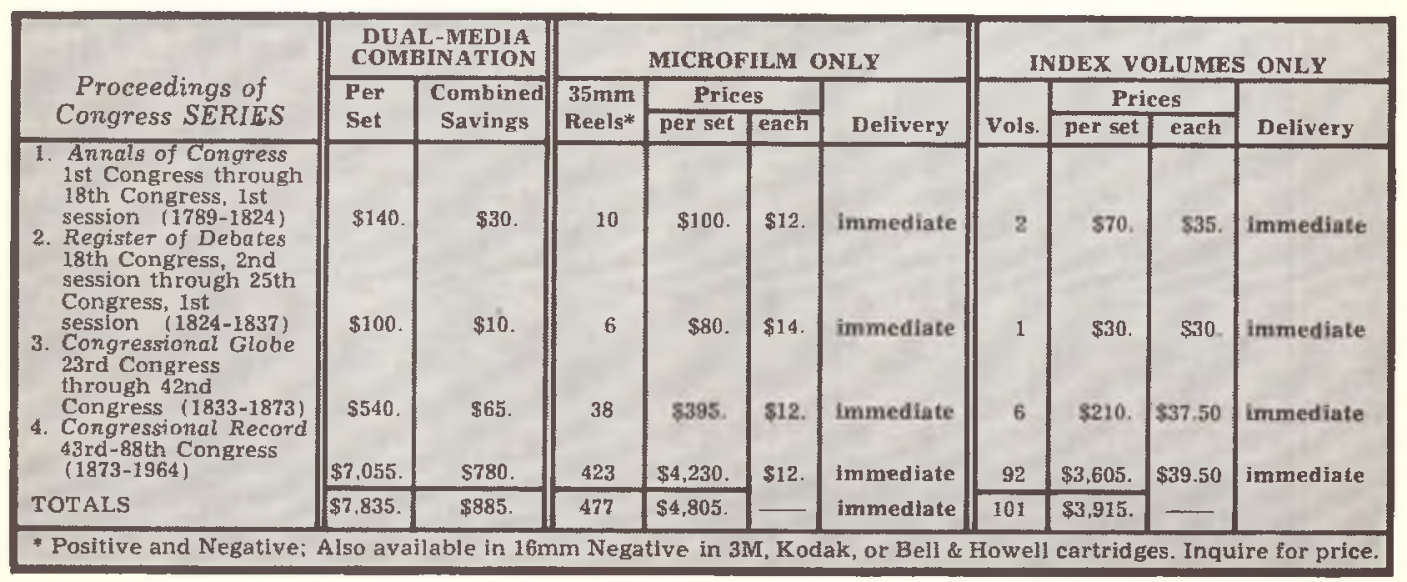

